\title{
A CONCRETIZAÇÃO DO PLANO DE SAÚDE PÚBLICA CONCERNENTE AO PROJETO BELO MONTE MEDIANTE DECISÃO ESTRUTURAL: EM BUSCA DA EFETIVIDADE DO PLENO ACESSO À JUSTIÇA
}

\author{
Vanessa Mascarenhas de Araújo ${ }^{1}$
}

\begin{abstract}
RESUMO: Esse artigo objetiva demonstrar a necessidade da eficácia e da eficiência do Plano de Saúde Pública referente ao Projeto Nacional da Usina Hidrelétrica (UHE) Belo Monte em prol do bem-estar da população local que vive na Área de Influência Direta (AID) do respectivo empreendimento mediante atuação do Estado-juiz, precisamente, através da decisão estrutural - instrumento processual essencial para a efetividade do acesso à justiça no caso em comento. Constata-se que a construção da Hidrelétrica de Belo Monte é um objetivo de Estado que está voltado ao objetivo fundamental desenvolvimento nacional; contudo, verifica-se que os impactos à saúde da população afetada não foram efetivamente minorados, necessitando-se, assim, da atuação do Poder Judiciário de modo a garantir o acesso à justiça como a porta de saída e, por conseguinte, garantir o direito fundamental à saúde. Mediante levantamento bibliográfico e documental, desenvolvem-se as seguintes temáticas: projeto UHE Belo Monte à luz do Poder Nacional; direito fundamental à saúde; decisão estrutural e acesso à justiça.
\end{abstract}

Palavras-chave: Acesso à justiça. Poder Judiciário. Decisão estrutural. Saúde Pública. Projeto Belo Monte.

\section{THE IMPORTANCE OF PUBLIC HEALTH PLAN'S EFFECTIVENESS AND EFFICIENCY REGARDING THE BELO MONTE HYDROELECTRIC PROJECT}

\begin{abstract}
This article aims to demonstrate a need for the effectiveness and efficiency of the Public Health Plan for the Belo Monte National Hydroelectric Power Plant Project for the welfare of the local population living in the Area of Direct Influence (AID) of the respective enterprise through the action of the State Judge, precisely through the structural decision essential procedural instrument for an effective access to justice in the case in question. It is observed that the construction of the Belo Monte Hydroelectric Plant is an objective of the State that is focused on the fundamental national development objective; However, it is verified that the health impacts of the affected population were not effectively smaller, thus requiring the Judiciary to act in order to guarantee access to justice as an exit door, thus guaranteeing the fundamental right the health. Bibliographical and documentary survey, developing the following steps: Belo Monte HPP project in light of the National Power; fundamental right to health; structure and access to justice.
\end{abstract}

Keywords: Access to justice. Judicial power. Structural decision. Public health. Belo Monte Project.

\footnotetext{
${ }^{1}$ Mestranda em Direito Público pela Faculdade de Direito da UFBA. Pós-graduanda em Direito Processual Civil pela UCSAL. Especialista em Política e Estratégia pela Associação dos Diplomados da Escola Superior de Guerra, Delegacia da Bahia, ADESGBA/Universidade do Estado da Bahia, UNEB. Membro do grupo de pesquisa Processo Constitucional e Direitos Fundamentais da UCSAL certificado pelo CNPq.
} 


\section{INTRODUÇÃO}

Em 21 de agosto de 2015, foi noticiado pelo Instituto Socioambiental (ISA) que a saúde da população afetada pela construção da Usina Hidrelétrica de Belo Monte estava em risco em razão do não cumprimento das condicionantes da hidrelétrica, as ações socioambientais de mitigação e prevenção de seus impactos. ${ }^{2}$

Em 30 de maio de 2016, também foi veiculado que a Norte Energia, empresa responsável pela usina, e a Prefeitura de Altamira, cidade mais próxima da barragem, não chegavam a um consenso acerca da obrigação de implantar e executar, integralmente, equipamentos e ações em prol da saúde, de modo a ocasionar a não conclusão de programas que tinham o fito de melhorar a vida de quem teve a rotina alterada por Belo Monte. ${ }^{3}$

Decerto, ao mesmo tempo em que se identifica a relevância da execução do projeto da Usina Hidrelétrica (UHE) Belo Monte no cenário nacional atual, percebe-se a importância da eficiência e da eficácia do seu respectivo Plano de Saúde Pública, componente do Plano Básico Ambiental, para prevenir e controlar impactos ambientais gerados sobre a saúde da população que vive na Área de Influência Direta (AID) de Belo Monte: Altamira, Anapú, Brasil Novo, Senador José Porfírio e Vitória do Xingu. ${ }^{4}$

Conforme destaca a Norte Energia ${ }^{5}$, o projeto UHE Belo Monte é estruturante para a política nacional de expansão da geração de energia elétrica, de modo a satisfazer, nos próximos anos, o imperativo da modicidade tarifária e a segurança energética do país.

Trata-se, pois, de um projeto de grande vulto que precisa ser executado juntamente com demais ações estratégicas que venham a mitigar os impactos ambientais negativos ocasionados no decorrer dessa execução.

\footnotetext{
${ }^{2}$ Noticiado pelo Instituto Socioambiental (ISA), em sítio eletrônico, em 21 de agosto de 2015: Os problemas na saúde indígena voltaram a ser foco das atenções em Altamira (PA), na última terça-feira (18), durante uma audiência pública. Com a usina de Belo Monte praticamente pronta, o Ministério Público Federal (MPF) convocou os índios afetados, Fundação Nacional do índio (Funai) e outros órgãos de governo envolvidos para um balanço sobre a situação na região afetada pela usina. Disponível em: <https://www.socioambiental.org/pt-br/noticiassocioambientais/em-audiencia-sobre-belo-monte-mpf-denuncia-obrigacoes-descumpridas-na-saude-indigena>. Acesso em fevereiro de 2018.

${ }^{3}$ Título da notícia: "Construção de Belo Monte afeta a vida de comunidades no sudoeste do Pará. Moradores de Altamira, indígenas e pescadores denunciam impactos. Hidrelétrica construída no rio Xingu iniciou operações em abril deste ano.” Disponível em: < http://g1.globo.com/pa/para/noticia/2016/05/construcao-de-belo-monte-afetavida-de-comunidades-no-para.html>. Acesso em março de 2018.

${ }^{4}$ Ações de saúde - SESPA e Norte Energia na área de abrangência de Belo Monte, Estado do Pará. Disponível em: <https://www2.mppa.mp.br/sistemas/gcsubsites/upload/41/ACOES\%20BELO\%20MONTE.pdf>. Acesso em março de 2018.

${ }^{5}$ Segundo a Norte Energia, a construção da UHE Belo Monte se insere na necessidade de aproveitar o valioso potencial hidroelétrico oferecido pelo rio Xingu, permitindo converter a riqueza natural em instrumento para o desenvolvimento da região e do país como um todo. Disponível em: < http://www.norte.libradesign.com.br/pt/energia-eletrica/>. Acesso em março de 2018.
} 
Ante a relevância deste projeto na conjuntura política nacional atual, estando envolvidos diversos atores e coadjuvantes, destacando-se, entre aqueles, os povos indígenas, os ribeirinhos, a questão norteadora deste presente estudo foi a seguinte: o projeto UHE Belo Monte foi e está sendo executado à luz da Expressão Psicossocial do Poder Nacional? Parte-se da hipótese de que apenas a Expressão Econômica esteja sendo considerada na execução desse projeto.

Outra suposição apontada corresponde ao fato de que, tanto o Poder Público, quanto o empreendedor responsável pela execução do projeto estejam estabelecendo medidas para mitigar ou compensar os impactos ambientais sobre a saúde da população. Contudo, tais medidas estão sendo suficientes para assegurar e promover o direito fundamental em comento? Se negativo, de que forma o Estado-juiz pode atuar a fim de garantir e promover este direito aos povos afetados pela construção deste megaprojeto, e, por conseguinte, garanti-los o pleno acesso à justiça?

Nesse sentido, o presente trabalho de pesquisa teve como objeto de estudo o Plano de Saúde Pública concernente ao projeto da Usina Hidrelétrica Belo Monte, de modo a demonstrar a importância da sua eficácia e da sua eficiência, haja vista a sua finalidade - fortalecer os serviços da rede de saúde municipal da área de influência da usina hidrelétrica através de parcerias com gestor municipal, estadual e federal - mediante a atuação do Estado-juiz ante a ineficiência da atuação das demais instituições envolvidas na execução do projeto, seja a empresa, seja o Estado-administrador.

Busca-se apontar a decisão estrutural como elemento propulsor do pleno acesso à justiça nos casos em que, nos pólos adversos, encontram-se direitos e interesses assegurados na Constituição Federal.

A pesquisa teve como base metodológica, além da pesquisa documental atinente ao projeto Belo Monte e o Plano de Saúde Pública respectivo, a revisão de literatura no que diz respeito à saúde como direito fundamental, a atuação do Poder Judiciário e o acesso à justiça, além de outras fontes teóricas que embasaram os termos eficácia, eficiência e o projeto UHE Belo Monte à luz do Poder Nacional calcado na doutrina básica de Mobilização Nacional desenvolvido pela Secretaria de Assessoramento da Defesa Nacional.

\section{PROJETO UHE BELO MONTE À LUZ DO PODER NACIONAL}


O projeto UHE Belo Monte foi retomado pelo Governo Federal após autorização do Congresso Nacional mediante Decreto Legislativo N. ${ }^{\circ} 788 / 2005^{6}$, com vistas a promover o setor energético brasileiro, e, consequentemente, a fortalecer o desenvolvimento socioeconômico do país quando do Aproveitamento Hidroelétrico Belo Monte. Através desse projeto nacional, constata-se que o governo acrescentará mais de 11 mil megawatts (MW) de capacidade instalada à matriz energética nacional. ${ }^{7}$

Segundo Norte Energia, o sistema energético brasileiro é atendido fundamentalmente pela geração hidrelétrica, correspondendo ao percentual de 80\% (oitenta por cento), sendo complementado por usinas térmicas e fontes alternativas, como energia eólica e biomassa.

De acordo com a Eletrobrás, o Governo Federal tem planos de produzir mais energia até o ano de 2030, sendo que o projeto Belo Monte integra um desses planos, bem como representa 5,5\% (cinco e meio por cento) do que o Brasil precisa atualmente. Ademais, a sua retomada deve-se a um dos objetivos do Programa de Aceleração do Crescimento (PAC), programa criado em 2007 pelo Governo Federal, cujo objetivo foi promover a retomada do planejamento e execução de grandes obras de infraestrutura social, urbana, logística e energética do país, contribuindo para o seu desenvolvimento acelerado e sustentável. ${ }^{8}$

Ante o exposto, verifica-se que o referido projeto se insere nas Expressões do Poder Nacional $^{9}$, precipuamente na Expressão Política, vez que se trata de um projeto que está em consonância com as ações estratégias de cunho nacional; na Expressão Econômica, vez que busca satisfazer as necessidades vitais da população, além de proporcionar o crescimento econômico da Nação; na Expressão Científica e Tecnológica, por se tratar de um projeto de recurso hídrico, o que envolve conhecimento, exploração, aperfeiçoamento e controle dos recursos naturais para o fortalecimento do Poder Nacional, bem como por ser um projeto de grande vulto, que deve ser desenvolvido mediante análise de impacto ao meio ambiente; e, por fim, na Expressão Psicossocial, vez que, no decorrer da sua execução, faz-se necessário que os

\footnotetext{
${ }^{6}$ Autoriza o Poder Executivo a implantar o Aproveitamento Hidroelétrico Belo Monte, localizado em trecho do Rio Xingu, no Estado do Pará, a ser desenvolvido após estudos de viabilidade pela Centrais Elétricas Brasileiras S.A. - Eletrobrás.

7Informação constante no documento elaborado pela Empresa de Pesquisa Energética - Ministério de Minas e Energia - Projeto da Usina Hidrelétrica de Belo Monte - Perguntas Mais Frequentes., fevereiro de 2011. Disponível em <http://www.mme.gov.br/documents/10584/1590364/BELO_MONTE__Perguntas mais Frequentes.pdf/20edbaee-c096-49a8-b117-22bf0262c80a >. Acesso em fevereiro de 2018. 8 Disponível em <http://www.pac.gov.br/sobre-o-pac>. Acesso em fevereiro de 2018.

9 As Expressões do Poder Nacional são assim identificadas pela Doutrina Básica de Mobilização Nacional Secretaria de Assessoramento da Defesa Nacional. Disponível em: < http://www.defesa.gov.br/arquivos/File/legislacao/emcfa/publicacoes/dbmn_doutrinabasicademobilizacaonacion al.pdf>. Acesso em março de2018.
} 


\section{A CONCRETIZAÇÃO DO PLANO DE SAÚDE PÚBLICA CONCERNENTE AO PROJETO BELO MONTE MEDIANTE DECISÃO ESTRUTURAL: EM BUSCA DA EFETIVIDADE DO PLENO ACESSO À JUSTIÇA}

níveis de bem-estar sejam garantidos à pessoa humana afetada pela execução deste megaprojeto, em destaque, o direito à saúde.

\section{O DIREITO FUNDAMENTAL À SAÚDE}

O direito à saúde é imprescindível a todos, sem distinção de qualquer natureza, e está diretamente ligado ao direito à vida, bem maior de toda pessoa humana.

Segundo Aristóteles (384-322, A.C.), a saúde é preferível à força e à beleza, pois a primeira é inerente tanto ao úmido como ao seco, tanto ao quente como ao frio - em suma, a todos os constituintes primários de um animal -, ao passo que as outras são inerentes ao que é secundário, sendo a força uma característica dos tendões e dos músculos, enquanto a beleza, segundo se supõe geralmente, consiste numa certa simetria dos membros. ${ }^{10}$

A Organização Mundial de Saúde (OMS) conceitua esse direito fundamental como "um estado de completo bem-estar físico, mental e social, e não consiste apenas na ausência de doença ou de enfermidade” (OMS, 1946), tendo o Governo a responsabilidade pela saúde da sua Nação.

Este conceito, contudo, encontra-se incompleto nos dias atuais, haja vista a saúde ser resultante das condições de alimentação, habitação, educação, renda, meio ambiente, trabalho, transporte, emprego, lazer, liberdade, acesso e posse da terra e acesso aos serviços de saúde. ${ }^{11}$

Tem-se a saúde, portanto, como necessidade humana cuja concretização depende de um "conjunto de condições, bens e serviços que permitem o desenvolvimento individual e coletivo de capacidades e potencialidades, conforme ao nível de recursos sociais existentes e aos padrões culturais de cada contexto específico”. (LAURELL, 1997, p. 86).

Nesse sentido, a Carta Magna Brasileira de 1988, precisamente no artigo 196, estabelece que a saúde, além de ser um direito de todos, é dever do Estado, o qual é "garantido mediante políticas sociais e econômicas que visem à redução do risco de doença e de outros

10 Constante no texto Dos argumentos sofísticos; seleção de textos de José Américo Motta Pessanha; traduções de Leonel Vallandro e Gerd Bornheim da versão inglesa de W. A. Pickard. - São Paulo: Abril Cultural, 1978, p. 44.

11 Conceito de saúde formulado na VIII Conferência Nacional de Saúde (VIII CNS), realizada em Brasília, no ano de 1986. Também conhecido como "conceito ampliado" de saúde, foi fruto de intensa mobilização que se estabeleceu em diversos países da América Latina durante as décadas de 1970 e 1980, como resposta aos regimes autoritários e à crise dos sistemas públicos de saúde. In BATISTELLA, Carlos. Educação Profissional e Docência na Saúde: a formação e o trabalho do Agente Comunitário de Saúde. Disponível em: <http://www.epsjv.fiocruz.br/pdtsp/index.php?s_livro_id=6\&area_id=2\&autor_id=\&capitulo_id=14\&sub_capitu lo_id=26\&arquivo=ver_conteudo_2>. Acesso em fevereiro de 2018. 
agravos e ao acesso universal e igualitário às ações e serviços” (CRFB, 1988, art. 196) a fim de promovê-la, protegê-la e recuperá-la.

Conforme dispõe o artigo 197 do aludido documento constitucional, as ações e serviços de saúde são de relevância pública, cabendo ao Poder Público dispor sobre sua regulamentação, fiscalização e controle, enquanto que a execução pode ser realizada diretamente ou mediante terceiros, pessoa física ou jurídica de direito privado, objetivando, assim, concretizar o direito fundamental em comento.

É através do Sistema Único de Saúde (SUS), conjunto de ações e serviços federais, estaduais, distritais (DF) e municipais, que o Poder Público cumpre esse dever, regendo-se por princípios, tais como da descentralização, com direção única em cada esfera de governo, e do atendimento integral, com prioridade para as ações e serviços preventivos.

O controle e a fiscalização por parte do Poder Público devem ocorrer, por exemplo, em torno do Plano de Saúde Pública concernente ao Projeto UHE Belo Monte, objeto de estudo a ser abordado no tópico seguinte.

\subsection{O Plano de Saúde Pública concernente ao Projeto da Usina Hidrelétrica Belo Monte: importância da sua eficácia e da sua eficiência}

Embora seja atribuição do Poder Público efetivar o direito à saúde, a Constituição pátria facultou a assistência à saúde à iniciativa privada (CRFB, 1988, art. 199), de modo que instituições privadas podem participar de forma complementar do Sistema Único de Saúde, segundo diretrizes deste, mediante contrato de direito público ou convênio.

Um exemplo disto é o Plano de Saúde Pública, componente do Plano Básico Ambiental referente ao projeto da Usina Hidrelétrica (UHE) Belo Monte, que tem como escopo contribuir para o fortalecimento dos serviços da rede de saúde municipal da área de influência da usina hidrelétrica através de parcerias com gestor municipal (Secretarias Municipais de Saúde), estadual (Secretaria de Estado da Saúde) e federal (Ministério da Saúde) propondo o desenvolvimento de três programas, a saber: Incentivo à Estruturação da Atenção Básica à Saúde; Vigilância Epidemiológica, Prevenção e Controle de Doenças; e Ação para o Controle da Malária ${ }^{12}$.

12

Cf.

<http://licenciamento.ibama.gov.br/PBAs\%20Hidrel\%C3\%A9tricas/UHE\%20Belo\%20Monte/Volume\%20III\% 20-\%20Tomo\%202\%20-\%20Item\%2007\%20a\%2009/VOL\%20III\%20-\%20TOMO\%202\%20-\%208\%20\%20plano\%20saude.pdf> . Acesso em fevereiro de 2018. 


\section{A CONCRETIZAÇÃO DO PLANO DE SAÚDE PÚBLICA CONCERNENTE AO PROJETO}

BELO MONTE MEDIANTE DECISÃO ESTRUTURAL: EM BUSCA DA EFETIVIDADE DO

PLENO ACESSO À JUSTIÇA

De acordo com a Empresa de Pesquisa Energética ${ }^{13}$, o projeto UHE Belo Monte está em consonância com o compromisso nacional de assegurar o desenvolvimento sustentável, além de propiciar uma nova fonte de energia elétrica importante com o intuito de gerar o crescimento econômico e demográfico do país, bem como melhorar as condições de vida das comunidades locais.

Em contrapartida, conforme Estudos de Viabilidade, composto pelo Estudo de Impacto Ambiental (EIA) e o Relatório de Impacto Ambiental (RIMA), documentos elaborados pelo empreendedor responsável do referido projeto, a construção dessa grande represa na região de Altamira, Bacia do Rio Xingu, estado do Pará, Brasil, gera impactos ambientais que afetam a saúde da população residente nos municípios que compõem a Área de Influência Direta (AID) da UHE Belo Monte e aquela atraída pelo empreendimento.

Dessa forma, o objetivo do Plano de Saúde Pública consiste em estabelecer um conjunto de medidas que contribuam para mitigar ou compensar impactos, tais como a dispersão ou introdução de doenças e agravos de saúde, principalmente as doenças de transmissão hídrica, as transmitidas por vetores que proliferam na água e as predispostas pela migração. Dentre as doenças transmissíveis e não transmissíveis destacam-se:

a malária, as leishmanioses tegumentar e visceral, dengue, febre amarela e outras arboviroses, esquistossomose, filarioses, tuberculose, hanseníase, infecções e parasitas intestinais, hepatites virais, febre tifóide e outras salmoneloses, leptospirose, cólera, infecção pelo HIV/AIDS e outras doenças sexualmente transmissíveis, etc. As doenças não transmissíveis mais frequentes em impactos ambientais de projetos hidrelétricos são: intoxicações por mercúrio, por cianobactérias, por agentes poluentes e outros; pragas de mosquitos; acidentes e violência como acidentes de trabalho e de transito, violência doméstica e as decorrentes da criminalidade, e desordens psicossociais como estresse, abuso de álcool e drogas ilegais. (NORTE ENERGIA, 2011, p. 157).

Tendo em vista os impactos ambientais negativos sobre a saúde da população local da área de influência do empreendimento elencados acima, observa-se a importância da eficiência e da eficácia do aludido Plano de Saúde Pública a fim de preveni-los, bem como a fim de

${ }^{13}$ Cf. < http://www.mme.gov.br/documents/10584/1590364/BELO_MONTE__Fatos_e_Dados.pdf/94303fc2d171-45be-a2d3-1029d7ae5aad>. Acesso em março de 2018. 
potencializar os impactos positivos e, consequentemente, proporcionar a valorização do Homem, origem, meio e fim do desenvolvimento, síntese das aspirações e interesses nacionais para o qual devem ser orientadas as políticas e as estratégias. ${ }^{14}$

De acordo com Richard Boyle (1989, p. 19), a eficiência e a eficácia são os principais indicadores de desempenho organizacional, sendo esta a coisa certa, o resultado, o objetivo; enquanto que aquela corresponde ao fazer certo, o meio para se atingir um determinado resultado. No entendimento de Peter Ferdinand Drucker (1964, p. 5-15), o gestor precisa pensar nos resultados desejados, nas prováveis restrições, nas futuras revisões nos pontos de controle e nas implicações de como ele administrará seu tempo, de modo a entender que ser eficaz é a função de todo e qualquer gestor.

No tocante aos serviços prestados à população, conforme destaca Carlos Pimenta (1998, p. 173-199), a eficiência é considerada como ampliação desses serviços, de forma a proporcionar satisfação do Homem em relação a estes e aos indicadores de desempenho no setor público.

Nesse sentido, pode-se afirmar que a eficiência do Plano de Saúde Pública diz respeito à execução de todos os programas que o integram de forma plena, correta de modo a satisfazer à população ao garantir o acesso à saúde; enquanto que a eficácia diz respeito ao seu objetivo, à sua missão, qual seja: fortalecer os serviços de saúde da rede municipal da área de influência da UHE Belo Monte para viabilizar ações de vigilância epidemiológica, monitoramento e controle de vetores; além de prevenir o aumento de casos de malária na região de implantação do empreendimento.

Decerto, a partir do momento em que não se constata a concretização do Plano de Saúde em comento por parte dos responsáveis primários, de modo a prejudicar a população interessada, nota-se lesão a direito fundamental da comunidade local afetada pelos impactos negativos da construção da hidrelétrica, sendo, então, de extrema importância, ao ser provocado, a atuação do Estado-juiz mediante o devido processo de modo a garantir o pleno acesso à justiça.

\section{ATUAÇÃO DO PODER JUDICIÁRIO MEDIANTE DECISÃO ESTRUTURAL: A EFETIVIDADE DO ACESSO À JUSTIÇA.}

\footnotetext{
${ }^{14}$ Conforme a Doutrina Básica de Mobilização Nacional sustentado pela a Escola Superior de Guerra do Brasil criada pela Lei n. ${ }^{\circ} 785$ de 20 de agosto de 1949, instituto de altos estudos, subordinado diretamente ao Ministro de Estado da Defesa. Ver em: <http://www.esg.br/images/manuais/ManualBasicoII2014.pdf>.
} 


\section{A CONCRETIZAÇÃO DO PLANO DE SAÚDE PÚBLICA CONCERNENTE AO PROJETO BELO MONTE MEDIANTE DECISÃO ESTRUTURAL: EM BUSCA DA EFETIVIDADE DO PLENO ACESSO À JUSTIÇA}

O acesso à justiça corresponde não somente a um direito fundamental social, mas, necessariamente, corresponde ao núcleo, ao "ponto central" ${ }^{15}$ da ciência processual contemporânea.

No que diz respeito ao princípio do acesso à justiça para a tutela de interesses transindividuais, este tem dimensão essencialmente coletiva e social, haja vista não atender de forma exclusiva um cidadão específico, de modo a nortear a solução de controvérsias limitadas ao círculo de interesse dessa pessoa, mas a uma coletividade (GRINOVER, 2007, p. 29). Seja no processo individual, seja no processo coletivo, de fato, o pleno acesso à justiça corresponde à efetividade das decisões judiciais.

Segundo o inciso IV do §1으 do art. 489 do CPC-2015, qualquer decisão judicial - sentença, interlocutória ou acórdão - não estará fundamentada caso o juízo respectivo não enfrentar todos os argumentos deduzidos no processo capazes de, em tese, infirmar a conclusão adotada pelo julgador.

Ademais, о §3ㅇ do art. 489, do CPC-2015 estabelece que a decisão judicial deve ser interpretada a partir da conjugação de todos os seus elementos e em conformidade com o princípio da de boa-fé.

Desta forma, a decisão, em sentido lato sensu, não basta, pois, ser interpretada em observância a todos os argumentos apresentados pelas partes, envolvendo as questões fáticas, as provas colacionadas aos respectivos autos, e as questões de direito; deve-se somar ao princípio da boa-fé.

De acordo com Nelson Nery Junior e Rosa Andrade Nery (2015, p. 1157), a inclusão da boafé no dispositivo em comento é desnecessária, já que esta é referência fundamental para todos aqueles que atuam no processo, de forma ainda mais clara do que ocorria no CPC/1973.

Contudo, parece que a inclusão do princípio da boa-fé não é "desnecessária" por tal motivo, caso contrário, a inclusão das normas fundamentais na Parte Geral do novo código de processo civil brasileiro, por este mesmo raciocínio, também não seria necessária no que diz respeito ao comportamento dos sujeitos processuais em uma determinada relação jurídica processual. Ademais, conforme enunciado n. 0378 do FPPC, a boa-fé processual orienta a interpretação da postulação e da sentença, permite a reprimenda do abuso de direito processual e das condutas dolosas de todos os sujeitos processuais e veda seus comportamentos contraditórios.

\footnotetext{
${ }^{15}$ Nas lições de Mauro Cappelletti in Acesso à Justiça, tradução de Ellen Gracie Northfleet. Porto Alegre, Fabris, 1988, p. 13, o "acesso" é, além do direito fundamental social, o ponto central da moderna processualística, estudo que "pressupõe um alargamento e aprofundamento dos objetivos e métodos da moderna ciência jurídica".
} 
Ressalta-se que, o texto de uma sentença ou decisão final da causa encerra um enunciado normativo, do qual se extrai a norma jurídica - resultado da interpretação que se faz de um texto normativo. Na verdade, de qualquer decisão se extrai a norma jurídica concreta, individualizada que resolve um determinado caso concreto; como também é possível extrair uma norma geral, construída a partir do caso concreto, que serve de modelo para casos semelhantes - constituindo em precedentes a serem seguidos em casos sucessivos CUNHA, 2015, 1237).

Dessa forma, interpretar a decisão judicial de acordo com a boa-fé é interpretá-la, ao máximo, de acordo com os limites da relação jurídica processual respectiva, devendo considerar a vontade das partes, a sua intenção, além dos usos e costumes locais.

Para que haja o pronunciamento de tal decisão judicial, necessário se faz a provocação da parte; e se tratando de casos complexos e que envolvam direitos coletivos, deve haver a provocação do representante adequado para a tutela dos direitos lesionados ou que estão na ameaça de serem lesionados. Como exemplo, temos o caso Belo Monte.

É inegável a complexidade do referido caso: por tratar de um dos objetivos fundamentais do Estado Brasileiro, mas, sobretudo, por tratar de direitos fundamentais das comunidades tradicionais e locais afetadas diretamente com a obra da usina hidrelétrica em comento.

De fato, cabe ao Estado Brasileiro, detentor do poder uno e indivisível - emanado do povo -, atuar, neste tipo de caso concreto, de forma a adequar o projeto de recurso hídrico que se diz necessário à nação brasileira à efetividade dos direitos fundamentais daqueles que são afetados diretamente. A partir do momento em que não haja cumprimento por parte do Poder Executivo no que diz respeito a esta adequação, após acionado, cabe ao Estado-juiz, mediante decisão estrutural, adjudicar direitos, bem como programar a execução do decidido.

Assim, através do processo jurídico social, adequando a sua estrutura aos princípios e limites constitucionais pátrios, pode-se ter a efetividade dos direitos fundamentais mediante decisão estrutural. Faz-se necessário compreender tal decisão como um dos mecanismos de efetivação dos direitos fundamentais substanciais. ${ }^{16}$

Ao qualificar o Estado como personagem garantidor da efetividade dos direitos fundamentais pretende-se demonstrar que, todos os seus "Poderes" exercidos por distintos

\footnotetext{
${ }^{16}$ Conforme destaca Wilson Alves de Souza, in Jurisdição, garantias, direitos e deveres fundamentais., p. 21, 2014, a efetivação dos direitos nem sempre acontece, o que torna "indispensável a previsão de direitos fundamentais processuais, como um dos mecanismos de tentativa de efetivação dos direitos fundamentais substanciais".
} 


\section{A CONCRETIZAÇÃO DO PLANO DE SAÚDE PÚBLICA CONCERNENTE AO PROJETO BELO MONTE MEDIANTE DECISÃO ESTRUTURAL: EM BUSCA DA EFETIVIDADE DO \\ PLENO ACESSO À JUSTIÇA}

órgãos têm o dever, no exercício das suas respectivas funções, sejam típicas, sejam atípicas, garantir e concretizar os direitos fundamentais.

Na verdade, o princípio da separação dos poderes encontra-se consagrado na Lei Maior como "um dogma fundamental, essencial à existência e sobrevivência de um Estado preocupado com os direitos fundamentais” (CUNHA JR., 2016, p. 883).

Entretanto, o referido princípio não pode ser interpretado de forma rígida, considerando tão-somente a independência dos poderes em separado, inexistindo qualquer tipo de subordinação, mas também a harmonia entre os órgãos do Poder político, no sentido de que haja um controle mútuo entre eles, visando ao "equilíbrio necessário à realização do bem da coletividade e indispensável para evitar o arbítrio e o desmando de um em detrimento do outro e especialmente dos governados” (SILVA, 1998, p. 114).

Dessa forma, nada obsta que um poder fiscalize, auxilie outro poder visando à efetividade dos direitos fundamentais. Nesse sentido, “esse sistema de interferências recíprocas, encerrado na conhecida fórmula checks and balances, já havia sido apontada por Montesquieu [...] como uma providência necessária para que um poder pudesse limitar o outro poder” (CUNHA JR., 2016, p. 883).

Remetendo ao Poder Judiciário, notadamente à figura do Estado-juiz, este tem como função típica a judiciária, no entanto, nada obsta a este fiscalizar, por exemplo, atos do Poder Executivo a fim de garantir a efetividade dos direitos fundamentais, inclusive, de modo a auxiliar no cumprimento de determinado programa oriundo do Poder Executivo.

A atividade jurisdicional configura-se em um dos institutos fundamentais formulados pelo enunciado doutrinário (Ciência ou Filosofia) ${ }^{17}$, neste caso, pela Teoria Geral do Processo. A esta, portanto, cabe à formulação do seu conceito jurídico fundamental, que deve corresponder ao cenário atual, a saber, o Estado Democrático Constitucional, de modo a adequar essa atividade essencial para o desenvolvimento do fenômeno jurídico processual às transformações do Direito Processual (legislação processual - regras e princípios), bem como às transformações da sociedade, que busca a efetividade concreta da justiça, a pacificação social.

\footnotetext{
${ }^{17}$ Nesse sentido, Cândido Rangel Dinamarco (et.al., Teoria Geral do Processo. 29a ed., SP: Malheiros Editores Ltda., 2013, p. 29) diz que: “conhecer o processo e conhecer sua teoria geral é estar consciente de que toda essa ciência gira em torno da jurisdição exercida pelo juiz, da ação que o demandante exerce ao provocar o exercício da jurisdição, da defesa que o demandado tem o direito de opor à pretensão do demandante e do processo mediante o qual o juiz exerce a jurisdição, o autor exerce a ação e o réu, a defesa”.
} 
A jurisdição corresponde à função atribuída a terceiro imparcial com o fito de realizar o Direito de modo imperativo e reconstrutivo, ao tempo em que reconhece, efetiva, protege situações jurídicas concretamente deduzidas, em decisão insuscetível de controle externo e com aptidão para tornar-se indiscutível (DIDIER JR., 2016, p. 153).

Portanto, tanto as modificações na legislação processual, quanto na sociedade, são de extrema importância para a “(re)formulação” de um conceito jurídico fundamental da função jurisdicional. Não se pode concebê-la meramente como instrumento de resolver um conflito de interesses entre as partes, substituindo suas vontades pela vontade da lei, sendo este o tradicional entendimento doutrinário ${ }^{18}$.

Deve-se entender a atividade jurisdicional à luz dos valores e das normas fundamentais constitucionais, que, por sua vez, refletem nos fatos sociais. Daí a relação do poder jurisdicional do Estado com a efetividade dos direitos fundamentais.

Os direitos fundamentais são compreendidos como aqueles positivados na Lei Maior pátria, seja a norma de direito fundamental tanto uma regra, quanto um princípio. ${ }^{19}$ Conforme destaca Ingo Wolfgang Sarlet, tais direitos constituem parâmetro hermenêutico e valores superiores de toda a ordem constitucional e jurídica, indo ao encontro da melhor tradição do constitucionalismo na esfera dos direitos fundamentais (SARLET, 2009, p. 66). Seja de qualquer dimensão, o poder público e os particulares encontram-se necessariamente vinculados a eles, quanto àquele, vale destacar a vinculação dos órgãos do Poder Judiciário.

No que concerne à vinculação aos direitos fundamentais, há que ressaltar a particular relevância da função exercida pelos órgãos do Poder Judiciário, na medida em que não apenas se encontram, eles próprios, também vinculados à Constituição e aos direitos fundamentais, mas que exercem, para, além disto, e em função disto, o controle da constitucionalidade dos atos dos demais órgãos estatais, de tal sorte que os tribunais dispõem, simultaneamente, do poder e do dever de não aplicar atos contrários à Constituição, de modo especial os ofensivos aos direitos fundamentais, inclusive declarando-lhes a inconstitucionalidade.

Embora essa vinculação do poder público aos direitos fundamentais não esteja previsto de forma expressa na Constituição pátria, ao contrário do que dispõe a Constituição de

\footnotetext{
${ }^{18}$ Este entendimento tradicional doutrinário é ressaltado pelo processualista civil Daniel Amorim Assumpção Neves in Manual de Direito Processual Civil. $2^{\text {a }}$ ed., Rio de Janeiro: Forense; São Paulo: Método, 2010, p. 3. ${ }^{19}$ Nesse sentido, Robert Alexy (in Teoria dos Direitos Fundamentais, tradução de Virgílio Afonso da Silva, SP: Ed. Malheiros, 2014, p. 144) destaca que, compreender as normas de direitos fundamentais apenas como regras ou apenas como princípios não é suficiente: "Um modelo adequado é obtido somente quando às disposições de direitos fundamentais são atribuídos tanto regras quanto princípios”.
} 


\section{A CONCRETIZAÇÃO DO PLANO DE SAÚDE PÚBLICA CONCERNENTE AO PROJETO BELO MONTE MEDIANTE DECISÃO ESTRUTURAL: EM BUSCA DA EFETIVIDADE DO \\ PLENO ACESSO À JUSTIÇA}

Portugal $^{20}$, o dispositivo constitucional referente à aplicabilidade imediata das normas definidoras dos direitos e garantias fundamentais - art. $5^{\circ}$, $\S 1^{\circ}$, CF/1988 - legitima essa vinculação, sendo dever do poder público respeitar e promover os direitos fundamentais.

A decisão estrutural refere-se a um dos institutos jurídicos timidamente utilizados no campo do direito processual civil brasileiro ${ }^{21}$ que, especificamente, é necessária e adequada quando se está diante de situações jurídicas complexas, por exemplo, no campo da tutela coletiva.

Trata-se de uma decisão judicial que é prolatada não perante uma estrutura clássica do processo civil brasileiro - caracterizada pela bipolarização; direitos contrários bem definidos e estabelecidos das partes, cabendo ao magistrado julgar sobre "aquilo" e nos exatos "limites daquilo" que é apresentado pela parte autora, em observância ao princípio da demanda; mas sim de um provimento judicial estrutural que se dá perante relações jurídicas complexas, sejam reguladas pelo direito privado, sejam reguladas pelo direito público. ${ }^{22}$

No tocante à análise da tutela coletiva à luz do direito processual brasileiro ${ }^{23}$, seja através do CPC/1973, seja através do CPC/2015, devem ser consideradas as regras e princípios dispostos na lei processual que podem ser utilizados no âmbito da tutela coletiva, haja vista o código de processo civil (tanto o de 1973, quanto o de 2015) não estabelecer um procedimento próprio, ditando suas regras e peculiaridades, para o processo em comento, o qual foi consolidado com o advento da Lei da Ação Civil Pública (Lei n. ${ }^{\circ}$ 7.347/85), posteriormente, aperfeiçoado com o advento do Código da Defesa do Consumidor (Lei n. ${ }^{\circ}$ 8.078/90) no que se refere à tutela dos direitos coletivos, difusos e os direitos individuais homogêneos (direitos

\footnotetext{
${ }^{20}$ Posiciona-se Ingo Wolfgang Sarlet (Op. cit., p. 365): “Diversamente do que enuncia o art. 18/1 da Constituição Portuguesa, que expressamente prevê a vinculação das entidades públicas e privadas aos direitos fundamentais, a nossa Lei Fundamental, neste particular, quedou silente na formulação do seu art. $5^{\circ}$, par. $1^{\circ}$, limitando-se a proclamar a imediata aplicabilidade das normas de direitos fundamentais.”

${ }^{21}$ Exemplo de medidas estruturais relatada por Sérgio Cruz de Arenhart, in Processo estruturais no direito brasileiro: reflexões a partir do caso da ACP do carvão, p. 11: “[...] tratamento dado à questão da mineração do carvão na área de Criciúma/SC.11 Em 1993, o Ministério Público Federal ajuizou ação civil pública (autos n. 93.8000533-4) junto à Justiça Federal de Criciúma, pretendendo impor às rés (mineradoras e a União, perfazendo um total de 24 réus) a realização e a concretização de um projeto de recuperação ambiental da região degradada pela mineração.” Disponível em: $<$ https://www.dropbox.com/s/piykooailsreu61/29_aula_sergio_arenhart_01.docx?dl=0 $>$ Acesso em setembro de 2016.

${ }^{22}$ Cf. ARENHART, Sérgio Cruz. Decisões estruturais no direito processual civil brasileiro. Disponível em: < https://www.academia.edu/9132570/Decis\%C3\%B5es estruturais_no_direito_processual_civil_brasileiro> Acesso em março de 2018.

${ }^{23}$ Conforme destaca Humberto Dalla Bernardinha de Pinho: "O direito processual brasileiro, originalmente filiado ás tradições dos ordenamentos de linha romano-germânica, foi concebido em bases eminentemente individualistas, refletindo a mentalidade e as necessidades da sociedade daquela época”. (Direito Processual Civil Contemporâneo, São Paulo: Saraiva, $5^{a}$ ed., p. 709).
} 
fundamentais da terceira dimensão - de titularidade coletiva e difusa, os transindividuais), sendo previsto, além na CF/88, nas demais leis infraconstitucionais.

Por outro lado, verifica-se também que é necessária adequar os institutos jurídicos a serem adotados no processo coletivo em razão da sua peculiaridade, onde se discute, por exemplo, direitos sociais, a tutela do patrimônio público do Estado, que acaba por interferir na gestão da política pública:

Percebeu-se que muitas decisões sobre questões coletivas exigem soluções que vão além de decisões simples a respeito de relações lineares entre as partes. Exigem respostas difusas, com várias imposições ou medidas que se imponham gradativamente. São decisões que se orientam para uma perspectiva futura, tendo em conta a mais perfeita resolução da controvérsia como um todo, evitando que a decisão judicial se converta em problema maior do que o litígio que foi examinado. ${ }^{24}$ (ARENHART, 2016. Decisões estruturais no direito processual civil brasileiro. Disponível em: $<$ https://www.academia.edu/9132570/Decis\%C3\%B5es_estruturai s_no_direito_processual_civil_brasileiro $>$. Acesso em março de 2018).

Verifica-se que, os pontos que a distinguem das demais são decorrentes da postura do magistrado perante a situação jurídica a ser enfrentada; ou seja, a intervenção judicial dar-se-á através de técnicas criativas, capazes de, ao menos, servir como centelha inicial do aperfeiçoamento de instituições e políticas públicas. ${ }^{25}$

Dentre os pontos que a diverge das demais, estão: a prolação da primeira decisão mais genérica, principiológica, cuja função principal é estabelecer a “primeira impressão” sobre as necessidades da tutela jurisdicional e, em momento posterior, a exigência de outras decisões a fim de solucionar problemas e questões pontuais surgidas na implementação da 'decisãonúcleo’, ou para a especificação de alguma prática devida - provimentos em cascata ${ }^{26}$; a decisão estrutural pode impor um plano de ação, ou delegar a criação de um plano a ser implantado por uma entidade pública ou privada; a necessidade de constante fiscalização a fim de acompanhar

\footnotetext{
${ }^{24}$ Cf. ARENHART, Sérgio Cruz. Decisões estruturais no direito processual civil brasileiro. Disponível em: < https://www.academia.edu/9132570/Decis\%C3\%B5es_estruturais no direito_processual_civil_brasileiro>

Acesso em março de 2018.

${ }^{25}$ Ibidem.

${ }^{26}$ Cf. ARENHART, Sérgio Cruz. Decisões estruturais no direito processual civil brasileiro. Disponível em: $<\underline{\text { https://www.academia.edu/9132570/Decis\%C3\%B5es_estruturais_no_direito_processual_civil_brasileiro> }}$ Acesso em março de 2018.
} 


\section{A CONCRETIZAÇÃO DO PLANO DE SAÚDE PÚBLICA CONCERNENTE AO PROJETO BELO MONTE MEDIANTE DECISÃO ESTRUTURAL: EM BUSCA DA EFETIVIDADE DO PLENO ACESSO À JUSTIÇA}

o cumprimento das medidas estabelecidas pelo Poder Judiciário, sendo limitado pela justificação da decisão judicial, vez que o poder estatal deve atuar de maneira razoável, proporcional e legítima. ${ }^{27}$

Conforme destaca Owen Fiss, o sistema de reforma estrutural não tem o cunho individualista, tampouco é caracterizado pela não participação do Poder Judiciário nas questões de política pública; ao contrário, o Estado-juiz dirige e rege a reconstrução das instituições:

Adjudication é um remédio tradicional na jurisprudência anglo-americana, mas, mormente no passado, sua ação se limitava a suspender ou evitar algum evento isolado. Entretanto, nas mãos do Poder Judiciário federal que optou pela liquidação do sistema de discriminação por tipo de raça e pela reorganização das burocracias que o implicavam, a injuction deixou de ser um instrumento para interromper um evento discreto qualquer, para se tornar o meio formal em virtude do qual o juiz dirige e rege a reconstrução continuada das instituições - a "injunction estrutural” (FISS, 2004, p. 30).

Para o autor, a adjudicação consiste em um processo social através do qual os juízes dão sentindo aos valores públicos. Nestas decisões não se impõem uma única consequência, tendo um “vencedor” e um “perdedor”, mas, sim, há amplitude das medidas determinadas e a variação do conteúdo da decisão ao longo do tempo em razão da modificação das condições da causa, como forma de atender ao interesse público, especificamente no que diz respeito à efetividade dos direitos fundamentais:

É preciso um juiz que, consciente de seu papel e prudente no exercício da jurisdição, tenha condições de oferecer à sociedade uma solução factível e razoável, no sentido de refletir da melhor maneira possível os valores públicos que devem ser o fim último da jurisdição (ARENHART, 2016. Decisões estruturais no direito processual civil brasileiro. Disponível em: $<$ https://www.academia.edu/9132570/Decis\%C3\%B5es_estruturai s_no_direito_processual_civil_brasileiro> . Acesso em março de 2018.).

\footnotetext{
${ }^{27}$ Ibidem.
} 
Faz-se necessário, pois, desmitificar a rigidez do princípio da separação dos poderes a fim de que o poder jurisdicional possa ser exercido de forma a atender de forma eficiente e eficaz o princípio do acesso à justiça, que diz respeito não somente à "porta de entrada”, mas também a “porta de saída” (SOUZA, 2011, p. 337).

Ao retornamos à análise do caso concreto Belo Monte, na medida em que o Ministério Público Federal propõe demanda, perante a Justiça Federal em Altamira (PA) ${ }^{28}$, em virtude da constatação de ilegalidades no que tange à obrigação de arcar com medidas de reparação por perdas sociais e culturais, assim como pelos abalos causados aos povos impactados, dentre os pedidos corresponderem à efetividade do direito à saúde, precisamente, a intervenção judicial no Plano de Saúde Pública para a sua concretização, o Estado-juiz deve atuar não mediante uma decisão única, mas mediante decisão estrutural, de modo a acompanhar e determinar medidas eficazes no cumprimento das ações previstas no referido Plano de Saúde Pública, componente do Plano Básico Ambiental.

Deve-se considerar, ainda, que o Plano de Saúde Pública corresponde a um método de planejamento estratégico, isto é, um processo dinâmico, permanente e continuado de racionalização das decisões políticas e das ações estratégicas decorrentes. ${ }^{29}$ Contudo, no caso em análise, conforme destacada por , não houve uma definição de indicadores de saúde para acompanhamento do projeto de maneira contínua e sistemática, bem como mostrou-se ausente um sistema de fiscalização das ações e atividades do projeto e da capacidade institucional para tal acompanhamento. ${ }^{30}$

Conforme destaca Jorge de Oliveira Vargas (2009, p. 12), é importante garantir o início e o fim do processo, de modo que o direito ou a expectativa de direito não seja sufocado. Não se pode admitir a simplificação do acesso à justiça à mera admissão à relação jurídico processual daqueles que estão lesionados ou se encontram na ameaça de serem, mas, notadamente, deve compreender a solução justa, a um processo de resultados, de modo a garantir o pleno acesso à justiça, seja no plano formal, seja no plano material.

\footnotetext{
${ }^{28}$ Disponível em <http://www.prpa.mpf.mp.br/news/2015/mpf-denuncia-acao-etnocida-e-pede-intervencaojudicial-em-belo-monte>. Acesso em fevereiro de 2018.

${ }^{29}$ Conforme a Doutrina Básica de Mobilização Nacional sustentado pela a Escola Superior de Guerra do Brasil criada pela Lei n. ${ }^{\circ} 785$ de 20 de agosto de 1949, instituto de altos estudos, subordinado diretamente ao Ministro de Estado da Defesa. Ver em: <http://www.esg.br/images/manuais/ManualBasicoII2014.pdf>.

${ }^{30} \mathrm{Cf}$. GRISOTTI, Márcia. A construção de relações de causalidade em saúde no contexto da Hidrelétrica de Belo Monte. In Dossiê: Impactos Socioambientais de Grandes Projetos de Infraestrutura. Disponível em: $<$ http://www.scielo.br/scielo.php?pid=S1414-753X2016000200287\&script=sci_arttext\&tlng=pt $>$. Acesso em março de 2018.
} 


\section{CONCLUSÃO}

No estudo realizado, verificou-se que, a construção da Usina Hidrelétrica de Belo Monte corresponde a um objetivo de Estado, uma vez que traduz a visão prospectiva que a sociedade nacional tem de seu futuro mediato ou imediato e a efetiva vontade de ver concretizadas suas aspirações, de modo a ultrapassar os compromissos que caracterizam a ação governamental.

Volta-se, assim, para o atendimento de interesses e aspirações de alta relevância para a consolidação e manutenção dos objetivos fundamentais da República Federativa do Brasil, sobretudo, no que diz respeito, especificamente, na garantia do desenvolvimento nacional.

No entanto, faz-se necessário, no decorrer da construção desse grande empreendimento nacional, a concretização do Plano de Saúde Pública, bem como das demais ações estratégicas, a fim de mitigar os impactos ambientais que afetam, negativamente, os mais diversos direitos fundamentais pertencentes à comunidade local, dentre eles, a saúde.

Deve-se haver o acompanhamento, a avaliação e a realimentação para atualização e correção de tais ações estratégicas. Desta forma, a partir do momento em que não haja cumprimento por parte do Poder Executivo no que diz respeito a este procedimento, cabe ao Estado-juiz, após acionado, mediante decisão estrutural, adjudicar direitos, bem como programar a execução do decidido.

Assim, através deste processo jurídico social, adequando a sua estrutura aos princípios e limites constitucionais pátrios, pode-se ter a efetividade dos direitos fundamentais mediante a decisão estrutural - composta por medidas justas e coerentes em busca da materialização do respectivo programa, plano, ação a ser executado para mitigar os impactos causados.

Faz-se necessário, pois, desmitificar a rigidez do princípio da separação dos poderes a fim de que a atividade jurisdicional possa ser exercida de forma a atender de forma eficiente e eficaz o princípio do acesso à justiça, que diz respeito não somente à porta de entrada, mas também a porta de saída de todo cidadão. 


\section{REFERÊNCIAS}

ALCANTARA, Christian Mendez. Constituição, Economia e Desenvolvimento: Revista da Academia Brasileira de Direito Constitucional. Curitiba, 2009, n. 1, Ago-Dez. p. 24-49.

ARENHART, Sérgio Cruz. Decisões estruturais no direito processual civil brasileiro. Disponível< https://www.academia.edu/9132570/Decis\%C3\%B5es_estruturais_no_direito_pr ocessual_civil_brasileiro> Acesso em abril de 2017

ARISTÓTELES, 384-322 A.C. Os Pensadores. Tópicos; Dos argumentos sofísticos; seleção de textos de José Américo Motta Pessanha; traduções de Leonel Vallandro e Gerd Bornheim da versão inglesa de W. A. Pickard. - São Paulo: Abril Cultural, 1978.

BATISTELLA, CARLOS. Educação Profissional e Docência na Saúde: a formação e o trabalho do Agente Comunitário de Saúde. Disponível em: < $\underline{w w w . f i o c r u z . b r}>$. Acesso em fevereiro de 2017.

BOYLE, RICHARD. Managing public sector performance. Dublin: Institute of Public Administration, 1989.

BRASIL. Constituição da República Federativa do Brasil. Brasília, DF, Senado, 1998.

BRASIL. EPE -

http://www.epe.gov.br/leiloes/documents/leil\%c3\%a3o\%20belo\%20monte/belo\%20m onte\%20-\%20fatos\%20e\%20dados\%20-\%20por.pdf.>Acesso em fevereiro de 2018.

BRASIL. Norma Operacional da Assistência - NOAS. Brasília, DF, Ministério da Saúde, Portaria ${ }^{\circ}$ 373, de 27 de fevereiro de 2002.

CAPPELLETTI, Mauro. Acesso à Justiça, tradução de Ellen Gracie Northfleet. Porto Alegre, Fabris, 1988.

DRUCKER, Peter Ferdinand. O Gestor Eficaz. Peter F. Drucker; tradução de Jorge Fontes; revisão técnica Sandra R. H. Mariano, Joysi Moraes. Rio de Janeiro: LTC, 2016.

FISS, Owen. Modelos de adjudicação/Models of adjudication. Cadernos de Direito FGV, São Paulo:FGV, Escola de Direito, 2004 - Bimestral. ISSN 1808-6780. 
GRISOTTI, Márcia. A construção de relações de causalidade em saúde no contexto da

Hidrelétrica de Belo Monte. In Dossiê: Impactos Socioambientais de Grandes Projetos de Infraestrutura. Disponível em: <http://www.scielo.br/scielo.php?pid=S1414753X2016000200287\&script=sci_arttext\&tlng=pt>. Acesso em março de 2018.

GRINOVER, Ada Pellegrini Grinover. Direito Processual Coletivo. In Teoria do processo: panorama doutrinário mundial. Eduaro Ferreira Jordão e Fredie Souza Didier Jr. (coord.) Saçvador: JusPodivm, 2007.

LAURELL, A. C. Impacto das políticas sociais e econômicas nos perfis epidemiológicos. In: BARRADAS, R. et al. (Orgs.) Eqüidade e Saúde: contribuições da epidemiologia. Rio de Janeiro: Editora Fiocruz, Abrasco, 1997.

OMS, Organização Mundial da Saúde. Constituição da Organização Mundial da Saúde (OMS/WHO) - 1946. USP. Disponível em: $<$ http://www.direitoshumanos.usp.br/index.php/OMSOrganiza\%C3\%A7\%C3\%A3o-Mundial-da-Sa\%C3\%BAde/constituicao-daorganizacao-mundial-da-saude-omswho.html> Acesso em agosto de 2015.

PIMENTA, C. C. A reforma gerencial do Estado brasileiro no contexto das grandes tendências mundiais. Revista de Administração Pública, 32 (5), 173-199, set./out. 1998.

SILVA, José Afonso. Curso de Direito Constitucional. 36a edição, rev. e atual. Editores Malheiros. São Paulo, 2013.

SOUZA, Wilson Alves de. Acesso à justiça. Salvador: Dois de Julho, 2011.

SOUZA, Wilson Alves de.Jurisdição, garantias, direitos e deveres fundamentais. Estudos de Direito Processual: um enfoque sob a ótica do acesso à justiça. Wilson Alves de Souza; Aldo Ribeiro Britto et al (coord.) - Salvador: Ed. Dois de Julho, 2014. 